\title{
Psychosocial Predictors of Work Ability in Morbidly Obese Patients: Results of a Cross-Sectional Study in the Context of Bariatric Surgery
}

\author{
Hinrich Köhler ${ }^{a}$ Valentin Markov ${ }^{b}$ Anna Watschke ${ }^{c}$ Kerstin Gruner-Labitzke ${ }^{a}$ \\ Clara Böker $^{d} \quad$ Julian Malld Christoph Kröger ${ }^{b}$ \\ a Department of General, Visceral, and Bariatric Surgery, Herzogin Elisabeth Hospital, Braunschweig, Germany; \\ ${ }^{\mathrm{b}}$ Department of Psychology, University of Hildesheim, Hildesheim, Germany; ' ${ }^{\mathrm{D}}$ Department of Psychology, University

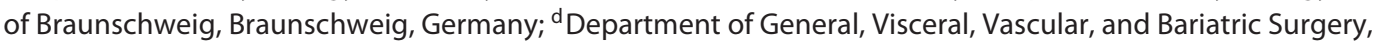 \\ Klinikum Nordstadt, Hanover, Germany
}

\section{Keywords}

Obesity · Work ability · Psychosocial predictors - Bariatric surgery

\begin{abstract}
Background: Obesity is associated with a higher risk of work disability and premature early retirement. Objective: The aim of this study was to examine psychosocial predictors for work ability prior to surgery. Methods: Based on a sample of 197 surgery-seeking obese patients (preoperative body mass index [BMI] above $35 \mathrm{~kg} / \mathrm{m}^{2}$ ) from a German bariatric surgery unit, the present cross-sectional study examined based on standardized self-rating measures whether depressive symptoms, dysfunctional eating behaviors, relationship satisfaction, and life satisfaction have a predictive value for work ability. Results: Considerable impairment of work ability was found in $51.8 \%$ of morbidly obese participants $(n=102)$. Multiple regression analyses revealed that older age, greater depressive symptoms, and lower life satisfaction were significant predictors of preoperative work ability. BMI, gender, relationship satisfaction, and dysfunctional eating behaviors did not predict work ability. Conclu-
\end{abstract}

karger@karger.com www.karger.com/ofa

Karger $\stackrel{\text { ' }}{5}$

GOPEN ACCESS
(C) 2020 The Author(s)

Published by S. Karger AG, Basel

This is an Open Access article licensed under the Creative Commons Attribution-NonCommercial-4.0 International License (CC BY-NC) (http://www.karger.com/Services/OpenAccessLicense), applicable to the online version of the article only. Usage and distribution for commercial purposes requires written permission. sions: Our findings might indicate the use of further psychosocial measures following bariatric surgery to increase work ability.

(C) 2020 The Author(s)

Published by S. Karger AG, Basel

\section{Introduction}

Obesity is a chronic disease, one that impairs quality of life as well as physical and mental health [1]. Obese people show a high prevalence of additional psychiatric disorders [2,3]. For, example, anxiety and depression are 3-4 times higher among the obese than normal-weight individuals [4]. Additionally, health-related quality of life is significantly impaired in the obese population with respect to social interaction, psychosocial functioning, and depression [5]. Yet health-related quality of life may improve after bariatric surgery intervention, with effects that can last for $>10$ years [6]. Following bariatric surgery, $20-51 \%$ of patients mentioned positive postoperative changes on relationship satisfaction and functioning indices; only $3-10 \%$ mentioned a negative impact [7]. 
The negative consequences of obesity can also include loss of work ability. Several studies have outlined an association between overweight and the inability to work due to illness [8]. For example, bariatric surgery candidates miss an average of 33 workdays due to illness or injury in the year prior to surgery, compared with only 3 days lost by a typical US worker for the same reason [9]. In a long-term, nationwide US study, Tunceli et al. [10] documented an association between being overweight and reduced employment, as well as self-reported work impairment. Bariatric surgery aims to reduce the risk of work disability and premature early retirement [11]. Work ability is associated with physical and mental health and is therefore compromised among the obese population. Previous studies reported negative effects of high physical workload and obesity on work ability $[12,13]$. Several studies investigated not only the psychosocial outcome variables after bariatric surgery, but also looked at their predictive value for work ability in obese subjects. Depression was identified as a strong independent predictor for work ability, while morbid obesity was revealed as a strong predictor of work impairment [14].

Depressive tendencies and quality of life were identified as significant psychosocial predictors for increased labor productivity and reduction of work-related impairment after bariatric surgery [15]. Only a few studies have investigated the work ability of bariatric candidates as a primary outcome, and these have only rarely reported any psychosocial predictors of work ability before and after bariatric surgical intervention $[6,7,15-17]$. Thus, it is still unclear which psychosocial factors can influence or predict work ability prior to bariatric surgery. Characteristics like reduced depressiveness or increased health-related quality of life are increasingly considered as success criteria after bariatric surgery. Further, positive couple relationships can enhance the health and wellbeing of all family members, whereas poor partnerships can increase suffering and negatively affect the health of all concerned [18].

The present study examines whether depressive symptoms, dysfunctional eating behavior, relationship satisfaction, and life satisfaction have predictive value for work ability. The impact of these factors on work ability in bariatric surgery candidates has not been assessed in previous studies to date. The predictive value of further variables such as age, body mass index (BMI), and gender on work ability are also investigated in the present study. We assumed that work ability is low in the obese population. Because mental health has an important impact on work ability, we hypothesized that such mental health predictors as level of depressive symptoms and of dysfunctional eating behavior would show a negative association with work ability, while social health predictors such as couples' relationship and life satisfaction would demonstrate a positive association. Finally, we hypothesized that the demographic variables age and BMI would show a negative association with work ability.

\section{Materials and Methods}

\section{Study Design}

The present work is part of an investigation performed according to a longitudinal design within General, Abdominal, and Bariatric Surgery Unit of Herzogin Elisabeth Hospital in Brunswick, Germany. Data were collected between September 2015 and June 2016. The total sample included 200 patients seeking bariatric surgery at the hospital. Patients scheduled for gastric bypass or sleeve gastrectomy were asked to complete several self-report questionnaires during preoperative visits to the surgical department.

All study participants received a comprehensive explanation of the surgery and were given a written informed consent form. Participation was completely voluntary. The study was approved by the Institutional Ethics Committee of the University of Brunswick (M-2015-07). Patients received no compensation for study participation. Inclusion criteria were as follows: age between 18 and 65 years, and preoperative BMI above $35 \mathrm{~kg} / \mathrm{m}^{2}$ (obesity grade 2 or 3). Exclusion criteria for participating in the assessment were insufficient German language skills, intellectual disability, developmental or learning disorders, a history of prior bariatric surgery, and current substance abuse. Three subjects were excluded because $>30 \%$ of the answers on their self-report questionnaires were missing. Self-reported sociodemographic variables such as age, sex, weight, height, and marital status are listed in Table 1.

Work ability, depressive symptoms, dysfunctional eating behavior, relationship satisfaction, and life satisfaction were assessed with the following standardized self-report measures. The work ability index (WAI) [19] is a questionnaire to assess work ability in the employed population. It is based on 10 items focusing on individual work ability, workload, and consequences of strain. The total score of the items forms a work ability index, that is, classified into four categories: bad, moderate, good, and very good. The WAI is one of the most-used and best-accepted instruments to measure work ability, as demonstrated by its availability in 21 languages [20]. Radkiewicz and Widerszal-Bazyl [21] found an acceptable internal consistency of Cronbach's $\alpha=0.72$. Symptoms of depression were assessed with the German version of the 9-item Patient Health Questionnaire-Depression Scale (PHQ-9). Each item is scored from 0 to 3 (not at all, on certain days, on more than half the days, and nearly every day), yielding a total score between 0 and 27. A total score $\geq 10$ indicates the presence of a major depressive disorder. Kroenke et al. [22] reported a good internal consistency of Cronbach's $\alpha=0.86$ to 0.89 . Abnormal eating behavior belongs usually to typical characteristics of obese patients. In our study, this was assessed with the screening measure for Detecting Abnormal Eating Behavior (KFzE) [23]. This questionnaire consists of 8 items with a range from 0 (never) to 6 (always). These assess 3 core symptoms (1, uncontrollable urge to eat; 2 , thinking of food; 3 , 
Table 1. Sociodemographic characteristics

\begin{tabular}{|c|c|c|c|c|}
\hline & \multicolumn{4}{|c|}{$n=191-197$} \\
\hline & M & SD & $n$ & $\%$ \\
\hline Women & & & 162 & 82.2 \\
\hline Age, years & 44.86 & 11.44 & 197 & \\
\hline \multicolumn{5}{|l|}{ Marital status } \\
\hline Single & & & 31 & 15.7 \\
\hline In relationship & & & 32 & 16.2 \\
\hline Married & & & 113 & 57.4 \\
\hline Divorced/widowed & & & 21 & 10.6 \\
\hline Children & & & 143 & 73.0 \\
\hline \multicolumn{5}{|l|}{ Years of education } \\
\hline 8 or less & & & 7 & 3.7 \\
\hline 9 & & & 72 & 37.5 \\
\hline 10 & & & 79 & 41.1 \\
\hline 13 & & & 8 & 4.2 \\
\hline 17 or more & & & 13 & 6.8 \\
\hline Professional training & & & 157 & 82.2 \\
\hline Current professional training & & & 120 & 62.5 \\
\hline $\mathrm{BMI}, \mathrm{kg} / \mathrm{m}^{2}$ & 47.70 & 7.45 & 191 & \\
\hline \multicolumn{5}{|l|}{ Psychotherapeutic treatment } \\
\hline Former & & & 93 & 47.9 \\
\hline Current & & & 31 & 15.8 \\
\hline
\end{tabular}

The sample size varies because of missing data. M, mean; SD, standard deviation; $n$, sample size; \%, percentile ranks.

feeling of satiety) and 5 symptoms with nonspecific aspects of eating abnormalities. A total score $\geq 25$ points to abnormal eating behavior. The KFzE was developed for German clinical populations and showed good psychometric characteristics such as testretest reliability $(r=0.92)$ and internal consistency values (Cronbach's $\alpha=0.87$ ) [23]. The relationship quality was assessed using the well-known Relationship Questionnaire (PFB) [24]. The short form of the PFB (PFB-K) comprises 9 items reflecting the 3 scales: Conflict Behavior, Tenderness, and Communication [25]. Item values are categorized into "never/nearly never," "infrequently," "often," and "very often" with a range from 0 to 3. Additionally, there is an item assessing the global relationship quality (how happy one is with his or her relationship) ranging from 0 to 6 . A total score of fewer than 12 points indicates a low relationship quality. Kliem et al. [25] found a good internal consistency value of Cronbach's $\alpha=0.84$ for the total PFB-K score. The Life Satisfaction Questionnaire $^{\text {Modules }}\left(\mathrm{FLZ}^{\mathrm{M}}\right)$ was used to measure current general life satisfaction [26]. This short measure comprises 8 items with values from 0 (unhappy) to 4 (very happy) and includes aspects such as friends, leisure activities, health, income and financial security, work, living situation, family life and children, relationship, and sexuality. A high score points to high life satisfaction. The internal consistency value turned out to be good (Cronbach's $\alpha=$ $0.82)$ [27].

\section{Data Analysis}

Data analyses were performed using the IBM Statistical Package for Social Sciences (IBM SPSS, version 26). A hierarchical multiple regression analysis was calculated to investigate the predictive value of self-rated depressive complaints, dysfunctional eating behavior, relationship satisfaction, life satisfaction, age, sex, and BMI as indicative of patients' ability to work. An analysis of missing values with SPSS (Missing Value Analysis) investigated the structure of missing data. It showed that up to $22 \%$ of the data were missing. The Little MCAR Test found that incomplete information was missing at random $\left(n=197, \chi^{2}(5,986)=612,698, p=0.10\right)$. To compensate for the loss of information, these data were substituted through a multiple imputation method [28]. According to this method, 10 imputed datasets were calculated to estimate the parameters of the missing values and fill them in to complete the dataset. Results are based on this imputed dataset.

\section{Results}

Table 2 presents the descriptive statistics of the WAI, PHQ-9, KFzE, PFB-K, and FLZ ${ }^{\mathrm{M}}$ scores. In the present study, internal consistency values varied between 0.76 and 0.85 and are classified as good psychometric characteristics. The mean value of the WAI-Index for all participants was found in the lower fourth ( $\leq 25$ th percentile) indicating poor work ability [29]. More than half ( $n=$ 102) of the participants were classified as being in this category. The evaluation of PHQ-9 showed no evidence of depressive disorders in $31.5 \%(n=62)$, mild symptoms 
Table 2. Descriptive data of the self-rating measures

\begin{tabular}{lrrllrr} 
Measures & M & SD & $\alpha$ & \multicolumn{2}{l}{ Range of values } & \multirow{2}{*}{ Skewness } \\
\cline { 5 - 6 } & & & & possible & available & \\
\hline WAI & 26.10 & 9.30 & 0.85 & $7-49$ & $7-48$ & -0.25 \\
PHQ-9 & 8.63 & 5.14 & 0.85 & $0-27$ & $0-23$ & 0.59 \\
KFzE & 23.07 & 8.01 & 0.80 & $0-48$ & $4-43$ & -0.13 \\
PFB-K & 17.15 & 5.54 & 0.84 & $0-27$ & $4-27$ & -0.33 \\
FLZ & 49.98 & 13.88 & 0.76 & $0-100$ & $21.40-93.58$ & 0.25 \\
\hline
\end{tabular}

M, mean; SD, standard deviation; $\alpha$, internal consistency coefficient Cronbach's $\alpha$; WAI, Work Ability Index; PHQ-9, Patient Health Questionnaire-Depression Scale; KFzE, Measure for Detecting Abnormal Eating Behavior; PFB-K, Short Relationship Satisfaction Questionnaire; FLZ ${ }^{\mathrm{M}}$, Life Satisfaction Questionnaire ${ }^{\text {Modules }}$. KFzE, PFB-K, and FLZ ${ }^{\mathrm{M}}$ are German abbreviations.

Table 3. Intercorrelation matrix

\begin{tabular}{llllll}
\hline Measures & WAI & PHQ-9 & KFzE & PFB-K & FLZ $^{\mathrm{M}}$ \\
\hline WAI & - & & & \\
PHQ-9 & $-0.45^{* *}$ & - & & \\
KFzE & -0.10 & $0.45^{* *}$ & - & - & - \\
PFB-K & $-0.26^{* *}$ & $-0.22^{*}$ & -0.08 & $0.31^{* *}$ & - \\
FLZ & $-0.54^{* *}$ & $-0.43^{* *}$ & $-0.17^{*}$ & \\
\hline
\end{tabular}

Pearson correlation coefficients $* p<0.05,{ }^{* *} p<0.01$. WAI, Work Ability Index; PHQ-9, Patient Health Questionnaire-Depression Scale; KFzE, Measure for Detecting Abnormal Eating Behavior; PFB-K, Short Relationship Satisfaction Questionnaire; FLZ ${ }^{\mathrm{M}}$, Life Satisfaction Questionnaire Modules. $^{\text {KFzE, PFB-K and FLZ }}{ }^{\mathrm{M}}$ are German abbreviations.

in $36.5 \%(n=62)$, and severe symptoms in $32.0 \%(n=63)$ of patients. Seventy-nine participants $(40.1 \%)$ achieved the cut-off value of the KFzE and were associated with abnormal eating behavior. In terms of relationship satisfaction, 44 participants (22.3\%) did not reach the cut-off value of the PFB-K and were classified as unsatisfied with their relationship. The average raw value of 50.05 points of the FLZ ${ }^{\mathrm{M}}$ in the current study corresponds to a percentile rank of 40 of a representative standard sample [27] pointing to less general life satisfaction in the sample of obese patients compared with the general population. The highest Pearson correlation coefficients of WAI was found with FLZ ${ }^{\mathrm{M}}$ and PHQ-9 followed by a smaller correlation coefficient with $\mathrm{PFB}-\mathrm{K}$ and a very small correlation coefficient with KFzE (see Table 3).

To detect the predictive value of the single items in determining the work ability of patients, a hierarchical multiple regression was performed. In the first block, the demographic variables age, sex, and BMI were taken gradu- ally into the model as controls, to detect a possible influence on WAI. In the second block, the values of the FLZ $^{\mathrm{M}}$, KFzE, PHQ-9, and PFB-K were included in the stepwise multiple regression to investigate a possible influence on WAI. Tests of multicollinearity showed a variance inflation factor between 1.00 and 1.26 , which is far below the critical value of 10 and so fulfils the statistical condition of no evidence of high multicollinearity of variables among them [30]. Furthermore, there was no evidence for a suppressor effect of any variable in the hierarchical model. Three variables predict the patients' work ability (WAI): age, life satisfaction (FLZ $\left.{ }^{\mathrm{M}}\right)$, and depressive complaints (PHQ-9). All other variables (sex, BMI, $\mathrm{KFzE}$, and PFB-K) revealed no sufficient variance explanation for the dependent variable "work ability"; thus, these variables were excluded as predictive values. Table 4 summarizes, and Figure 1 visualizes the results of the multiple regression analysis. 
Table 4. Hierarchical multiple regression analysis of demographic and self-rating measures variables on work ability

\begin{tabular}{|c|c|c|c|c|c|c|c|}
\hline \multirow{2}{*}{$\begin{array}{l}\text { Independent } \\
\text { variables }\end{array}$} & \multicolumn{7}{|c|}{ Dependent variable WAI } \\
\hline & B & $\mathrm{B}(\mathrm{SE})$ & $\beta$ & $t$ & $p$ value & $R$ & model $\left(\Delta R^{2}\right)$ \\
\hline Age, years & -0.25 & 0.05 & -0.31 & -5.614 & 0.000 & 0.682 & \\
\hline $\mathrm{FLZ}^{\mathrm{M}}$ & 0.31 & 0.04 & 0.46 & 7.503 & 0.000 & 0.325 & \\
\hline \multirow[t]{2}{*}{ PHQ-9 } & -0.41 & 0.11 & -0.28 & -3.737 & 0.000 & 0.652 & \\
\hline & & & & & & & $0.46^{\star * *}$ \\
\hline Sex & & & 0.048 & 0.906 & 0.366 & & \\
\hline BMI & & & -0.073 & -1.370 & 0.172 & & \\
\hline KFzE & & & 0.087 & 1.493 & 0.137 & & \\
\hline PFB-K & & & 0.051 & 0.912 & 0.363 & & \\
\hline
\end{tabular}

${ }^{* * *} p<0.001$. B, regression coefficient; B (SE), standard error of regression coefficient; $\beta$, standardized prediction value; $t$, test value of prediction value; $p$, significance value; $R$, correlation coefficient; $\Delta R^{2}$, corrected $R^{2}$, value for the explained variance of all significant variables together in the hierarchical model; WAI, Work Ability Index; PHQ-9, Patient Health Questionnaire-Depression Scale; KFzE, Measure for Detecting Abnormal Eating Behavior; PFB-K, Short Relationship Satisfaction Questionnaire; FLZ ${ }^{\mathrm{M}}$, Life Satisfaction Questionnaire ${ }^{\text {Modules }}$. KFzE, PFB-K and FLZ ${ }^{\mathrm{M}}$ are German abbreviations.

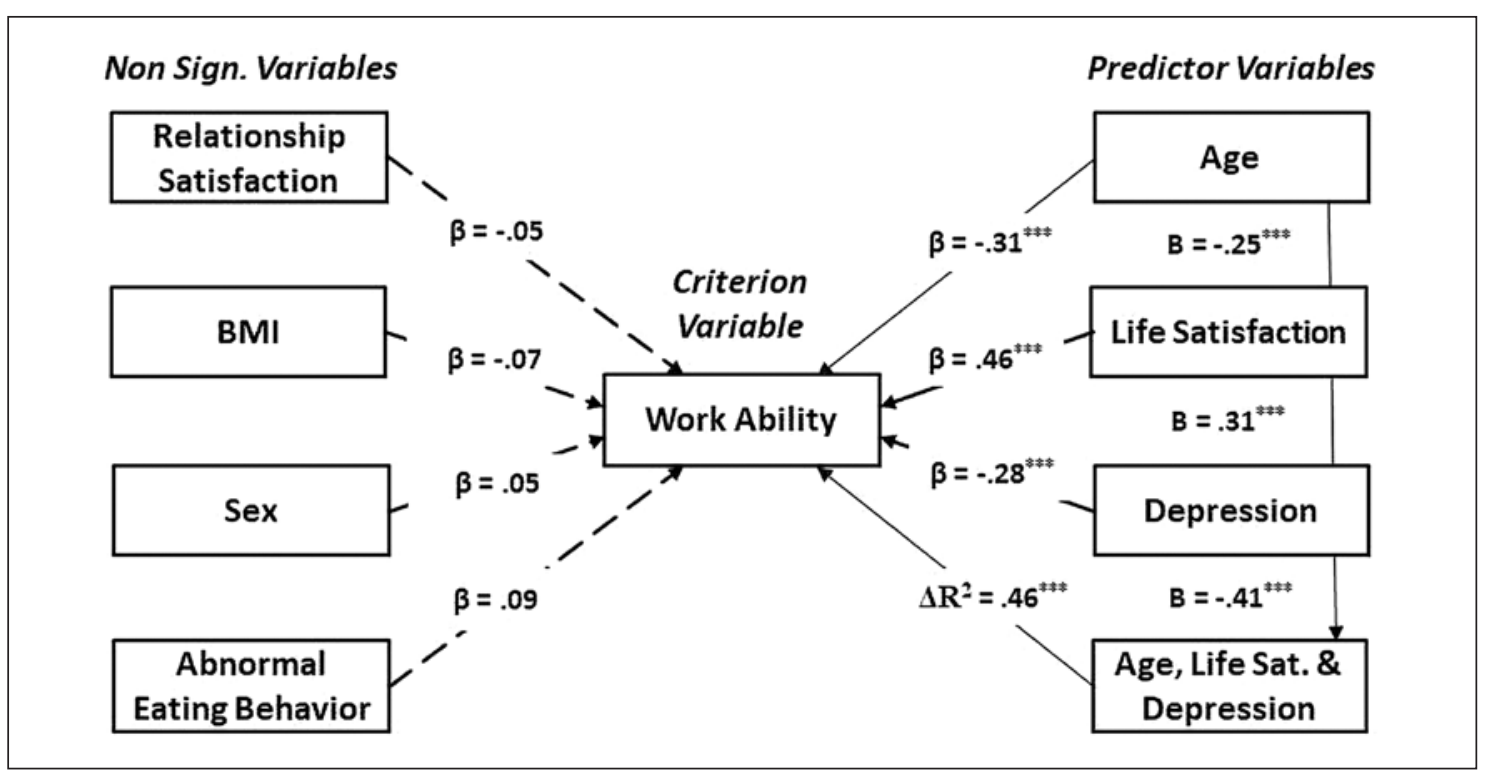

Fig. 1. Hierarchical multiple regression analysis of demographic and self-rating measures variables on work ability. Boxes display independent variables; the middle box includes criterion variable. Influences of non-significant variables on criterion variable are marked with dashed arrows and of significant (predictor) variables are marked with solid arrows. B, regression coefficient; $\beta$, standardized prediction value; $\Delta R^{2}$, corrected $R^{2}=$ value for the explained variance of all significant variables together in the hierarchical model. ${ }^{* * *} p<0.001$.

\section{Discussion}

The study results point to the predictive effects of age, life satisfaction, and depressive states on the work ability of morbidly obese subjects seeking bariatric surgery.
Other potential predictors such as BMI, sex, dysfunctional eating behavior, and relationship satisfaction showed no significant effects on work ability. These findings are partly in line with the theoretical background. Obese subjects usually suffer from poor physi-
60

Obes Facts 2021;14:56-63

DOI: $10.1159 / 000511735$
Köhler/Markov/Watschke/

Gruner-Labitzke/Böker/Mall/Kröger 
cal, mental, and social health [31]. This leads to lower subjectively experienced life satisfaction and to co-occurring mental disorders [2]. About half of the participants included in the present study had already been in psychotherapeutic treatment because of depressive complaints. Furthermore, $36.5 \%$ of them reported a mild level of depressive symptoms, and 32\% a severe level. Our findings were consistent with the meta-analysis of Dawes et al. [32], who reported a 23\% prevalence rate of any mood disorder among bariatric patients; hence, we found a higher number than the estimated rate of $10 \%$ in the general US population [33]. The prevalence rate of depression (19\%) was also higher among bariatric patients than in the general US population $(8 \%$ for depression) [34].

In scoring the WAI, we found that $51.8 \%$ of the participants in the present study reached a value that had to be classified as poor. According to a German reference group [29], the mean value of WAI of all participants is in the category of the lowest $15 \%$ ( $\leq 25$ percentile). These findings replicate previous investigations showing considerable impairment of work ability in the obese population [35]. In our sample, there is a high association between WAI and depression states. Also, Sockalingam et al. [15] reported a high impact of life satisfaction and depressive states on obese employees' work ability. The authors were able to show that improvements in depression and quality of life were significant predictors of work-related impairment and productivity and concluded that patients who experienced psychiatric distress prior to bariatric surgery had greater employment impairment and worse productivity. As a significant predictor of work ability, older age seems to have a negative effect on obesity and indicates high risk for premature work disability. This finding has also been demonstrated by van den Berg et al. [12] within a systemic literature review. Deficient work ability on the part of the obese leads to increased costs for employers, and reduced productivity in comparison to that of normal-weight workers [36]. Therefore, these obese individuals need to be treated at an early stage of the disease to maintain work ability. A return-to work program has shown small to moderate effects on the work ability of depressive patients [37]; this, too, could be implemented. Overall, there is only a limited body of knowledge in the literature that discusses the relationship between work ability and relationship satisfaction in the obese population. Among these, a French study reported impaired sexual behavior in the obese population [38]. Another study [39] described two large Swedish prospective cohorts with long-term fol- low-up assessments in which bariatric surgery was associated with increased incidence of divorce and separation, as well as increased incidence of marriage and new relationships; in summary, large changes in relationships at all levels. Against our hypothesis, and in contrast to the predictive value of life satisfaction, our study did not find an association between relationship satisfaction and work ability. Although relationship satisfaction is associated with health and wellbeing [18] and may be seen among the positive changes after bariatric surgery [7], the results of our study point to no significant correlation between relationship satisfaction and work ability. This fact is in line with the well-known work-family conflict investigated early on by Kahn et al. [40], and later postulated by Greenhaus and Beutell [41]. According to this theory, higher work engagement (for example) can increase work ability, but can concurrently decrease relationship satisfaction because of time-based, strain-based, or behavior-based conflicts.

Similar study results might indicate the predictive value of dysfunctional eating behavior on work ability. This association was hypothesized due to the positive changes in eating behavior following bariatric surgery $[6,7,15$, 17]. Yet, no impact of dysfunctional eating behavior on work ability was indicated in our findings, and to date, there is no study reporting any association between the two. To the best of our knowledge, this is the first study of bariatric surgery patients in which work ability predictors were examined in relation to psychosocial and sociodemographic factors. The strength of the present study rests on the inclusion of a homogenous study group of pre-bariatric candidates, along with recommended standardized measures.

There were several limitations that must be taken into consideration. First, we examined individuals seeking bariatric surgery only, and there was no normal-weight group that served as a control. Second, all participants attended a 6-month pre-surgery training program as a health insurance eligibility requirement for bariatric surgery reimbursement. Earlier research has demonstrated that individuals tend to underreport symptoms on diagnostic interviews relative to self-report inventories [42], and it is possible that participants underestimated their mental health symptoms in order to be reimbursed. Hence, our findings should be validated using other recruitment strategies, which may lead to different sample characteristics. Future research could examine both obese and normal-weight employees in terms of depressive complaints and days of incapacity to work, using expertratings and occupational health data, respectively. Third, 
we used a correlational design to study the relationship between the self-reported work ability and associated characteristics. Inferences of causality are unwarranted; hence, other study designs might complement our crosssectional study. For example, longitudinal data would better enable the exploration of the causal direction of effects. Finally, all the patients were living in Germany, and whether the results can be generalized to other countries and cultures is unknown. In addition, participation was completely voluntary and not representative of the entire obese population in Germany.

In summary, the results of our study support the thesis of considerable impairment of self-reported work ability in morbidly obese subjects. Furthermore, it was shown that depressive complaints, life satisfaction, and age could predict the level of work ability in this cohort. Against our hypotheses, relationship satisfaction and dysfunctional eating behavior could not predict work ability as well as it could indicate different levels of obesity within the morbidly obese group. The results of the current study lend additional support to the growing body of literature demonstrating the negative impact of morbidly obese subjects on work-related disability. Future studies are needed to clearly identify psychopathological and demographic predictors for work ability in the morbidly obese population in order to respond adequately and at an early stage of the disease.

\section{Statement of Ethics}

All procedures were in accordance with good clinical practice and within the Declaration of Helsinki. Written informed consent was obtained from all patients. The study was approved by the Institutional Ethics Committee of the University of Brunswick (M2015-07).

\section{Conflict of Interest Statement}

The authors declare that they have no conflict of interest.

\section{Funding Sources}

There are no funding sources to declare.

\section{Author Contributions}

H.K.: concept of study design, data acquisition, drafting of manuscript. V.M.: statistical analysis, drafting of manuscript. K.G.-L. and A.W.: data acquisition, critical revision of manuscript. C.B. and J.M.: concept of study design, critical revision of manuscript. C.K.: concept of study design, statistical analysis, critical revision of manuscript, data postprocessing. We confirm that the final version of this paper was read and approved by all of the authors.

\section{References}

1 World Health Organization. Obesity: preventing and managing the global epidemic. Report of a WHO consultation. World Health Organ Tech Rep Ser. 2000;894:i-xii.

2 Hauner H, Moss A, Berg A, Bischoff SC, Colombo-Benkmann $\mathrm{M}$, Ellrott $\mathrm{T}$, et al. Interdisziplinäre Leitlinie der Qualität S3 zur „Prävention und Therapie der Adipositas“. Adipositas. 2014;08(04):179-221.

3 Baumeister H, Härter M. Mental disorders in patients with obesity in comparison with healthy probands. Int J Obes. $2007 \mathrm{Jul} ; 31(7)$ : 1155-64.

4 Greenberg I, Perna F, Kaplan M, Sullivan MA. Behavioral and psychological factors in the assessment and treatment of obesity surgery patients. Obes Res. 2005 Feb;13(2):244-9.

5 Sjöström L. Review of the key results from the Swedish Obese Subjects (SOS) trial - a prospective controlled intervention study of bariatric surgery. J Intern Med. 2013 Mar;273(3): 219-34.

6 Karlsson J, Taft C, Rydén A, Sjöström L, Sullivan M. Ten-year trends in health-related quality of life after surgical and conventional treatment for severe obesity: the SOS inter- vention study. Int J Obes. 2007 Aug;31(8): 1248-61.

7 Herpertz S, Kielmann R, Wolf AM, Langkafel $M$, Senf W, Hebebrand J. Does obesity surgery improve psychosocial functioning? A systematic review. Int J Obes Relat Metab Disord. 2003 Nov;27(11):1300-14.

8 van Duijvenbode DC, Hoozemans MJ, van Poppel MN, Proper KI. The relationship between overweight and obesity, and sick leave: a systematic review. Int J Obes. 2009 Aug; 33(8):807-16.

9 Ewing BT, Thompson MA, Wachtel MS, Frezza EE. A cost-benefit analysis of bariatric surgery on the South Plains region of Texas. Obes Surg. 2011 May;21(5):644-9.

10 Tunceli K, Li K, Williams LK. Long-term effects of obesity on employment and work limitations among U.S. Adults, 1986 to 1999. Obesity (Silver Spring). 2006 Sep;14(9):163746.

11 Gryth K, Persson C, Näslund I, Sundbom M, Näslund E, Stenberg E. The Influence of Socioeconomic Factors on Quality-of-Life After Laparoscopic Gastric Bypass Surgery. Obes Surg. 2019 Nov;29(11):3569-76.
12 van den Berg TI, Elders LA, de Zwart BC, Burdorf $A$. The effects of work-related and individual factors on the Work Ability Index: a systematic review. Occup Environ Med. 2009 Apr;66(4):211-20.

13 Latza U, Liebers F, Franke F. Körperliche Beanspruchung und physische Belastungen bei der Arbeit - ein abnehmendes Public Health-Problem? Public Health Forum. 2013; 21(2):12.e1-3.

14 Arterburn D, Westbrook EO, Ludman EJ, Operskalski B, Linde JA, Rohde P, et al. Relationship between Obesity, Depression, and Disability in Middle-Aged Women. Obes Res Clin Pract. 2012 Jul;6(3):e197-206.

15 Sockalingam S, Wnuk S, Kantarovich K, Meaney C, Okrainec A, Hawa R, et al. Employment outcomes one year after bariatric surgery: the role of patient and psychosocial factors. Obes Surg. 2015 Mar;25(3):514-22.

16 Masheb RM, White MA, Toth CM, BurkeMartindale CH, Rothschild B, Grilo CM. The prognostic significance of depressive symptoms for predicting quality of life 12 months after gastric bypass. Compr Psychiatry. 2007 May-Jun;48(3):231-6. 
17 Wimmelmann CL, Dela F, Mortensen EL. Psychological predictors of mental health and health-related quality of life after bariatric surgery: a review of the recent research. Obes Res Clin Pract. 2014 Jul-Aug;8(4):e314-24.

18 Gruber KJ, Haldeman LA. Using the family to combat childhood and adult obesity. Prev Chronic Dis. 2009;6(3):A106.

19 Tuomi K, Ilmarinen J, Jahkola A, Katajarinne L, Tulkki A. Work Ability Index. 2nd ed. Helsinki: Finnish Institute of Occupational Health; 1998.

20 Amler N, Felder S, Mau W, Merkesdal S, Schöffski O; und Mitglieder des Arbeitsgruppe. [Instruments for Measuring the Effects of Early Intervention on Maintaining and Restoring Ability to Work in Germany: Opinion of an Interdisciplinary Working Group]. Gesundheitswesen. 2018 Jan;80(1):79-86.

21 Radkiewicz P, Widerszal-Bazyl M. Psychometric properties of Work Ability Index in the light of comparative survey study. Int Congr Ser. 2005;1280:304-9.

22 Kroenke K, Spitzer RL, Williams JB. The PHQ-9: validity of a brief depression severity measure. J Gen Intern Med. 2001 Sep;16(9): 606-13.

23 Wernze H, Rühl H. [Short questionnaire for detecting abnormal eating behavior (binge eating). Test results in 320 persons with normal weight and overweight/obesity]. Dtsch Med Wochenschr. 2007 Aug; 132(31-32): 1613-8.

24 Kliem S, Kröger C, Stöbel-Richter Y, Hahlweg K, Brähler E. Die faktorielle Struktur des Partnerschaftsfragebogens. Z Klin Psychol Psychother. 2012;41(2):109-13.

25 Kliem S, Job AK, Kröger C, Bodenmann G, Stöbel-Richter Y, Hahlweg K, et al. Entwicklung und Normierung einer Kurzform des Partnerschaftsfragebogens (PFB-K) an einer repräsentativen deutschen Stichprobe. Z Klin Psychol Psychother. 2012;41(2):81-9.
26 Henrich G, Herschbach P. Questions on Life Satisfaction (FLZ M): A short questionnaire for assessing subjective quality of life. Eur J Psychol Assess. 2000;16(3):150-9.

27 Daig I, Spangenberg L, Henrich G, Herschbach P, Kienast T, Brähler E. Alters- und geschlechtspezifische Neunormierung der Fragen zur Lebenszufriedenheit (FLZM) für die Altersspanne von 14 bis 64 Jahre. Z Klin Psychol Psychother. 2011;40(3):172-8.

28 Rubin DB. Multiple Imputation for nonresponse in surveys. New York: Wiley \& Sons; 1987.

29 Hasselhorn HM, Freude G. Der Work-ability-Index: Ein Leitfaden. Dortmund: Wirtschaftsverlag NW, Verlag für Neue Wissenschaft; 2007

30 Tabachnick BG, Fidell LS. Using Multivariate Statistics. 5th ed. New York: Allyn and Bacon; 2007.

31 Larsson U, Karlsson J, Sullivan M. Impact of overweight and obesity on health-related quality of life-a Swedish population study. Int J Obes Relat Metab Disord. 2002 Mar;26(3): 417-24.

32 Dawes AJ, Maggard-Gibbons M, Maher AR, Booth MJ, Miake-Lye I, Beroes JM, et al. Mental Health Conditions Among Patients Seeking and Undergoing Bariatric Surgery: A Meta-analysis. JAMA. 2016 Jan;315(2):150-63.

33 Kessler RC, Adler L, Ames M, Demler O, Faraone S, Hiripi E, et al. The World Health Organization Adult ADHD Self-Report Scale (ASRS): a short screening scale for use in the general population. Psychol Med. 2005 Feb; 35(2):245-56

34 Hudson JI, Hiripi E, Pope HG Jr, Kessler RC. The prevalence and correlates of eating disorders in the National Comorbidity Survey Replication. Biol Psychiatry. 2007 Feb;61(3):348-58.
35 Tonnon SC, Robroek SR, van der Beek AJ, Burdorf A, van der Ploeg HP, Caspers M, et al. Physical workload and obesity have a synergistic effect on work ability among construction workers. Int Arch Occup Environ Health. 2019 Aug;92(6):855-64.

36 Andersen LL, Izquierdo M, Sundstrup E. Overweight and obesity are progressively associated with lower work ability in the general working population: cross-sectional study among 10,000 adults. Int Arch Occup Environ Health. 2017 Nov;90(8):779-87.

37 Finnes A, Enebrink P, Ghaderi A, Dahl J, Nager A, Öst LG. Psychological treatments for return to work in individuals on sickness absence due to common mental disorders or musculoskeletal disorders: a systematic review and meta-analysis of randomized-controlled trials. Int Arch Occup Environ Health. 2019 Apr;92(3):273-93.

38 Bajos N, Wellings K, Laborde C, Moreau C CSF Group. Sexuality and obesity, a gender perspective: results from French national random probability survey of sexual behaviours. BMJ. 2010 Jun;340:c2573.

39 Bruze G, Holmin TE, Peltonen M, Ottosson J, Sjöholm K, Näslund I, et al. Associations of Bariatric Surgery With Changes in Interpersonal Relationship Status: Results From 2 Swedish Cohort Studies. JAMA Surg. 2018 Jul;153(7):654-61.

40 Kahn RL, Wolfe DM, Quinn RP, Snoek JD, Rosenthal RA. Organizational stress: Studies in role conflict and ambiguity. London: John Wiley; 1964.

41 Greenhaus J, Beutell N. Sources of conflict between work and family roles. Acad Manage Rev. 1985;10(1):76-88.

42 Cassin S, Sockalingam S, Hawa R, Wnuk S, Royal S, Taube-Schiff M, et al. Psychometric properties of the Patient Health Questionnaire (PHQ-9) as a depression screening tool for bariatric surgery candidates. Psychosomatics. 2013 Jul-Aug;54(4):352-8. 